\title{
Perception of Smile Esthetics by Orthodontists, Non-Dental and Dental Students: A Comparative Study
}

$\begin{array}{ll}\text { Khurram Parvez Sardar }^{1} & \text { BDS, MDS } \\ \text { Alizey Shahid }^{2} & \text { BDS } \\ \text { Ahmed Moiz }^{3} & \text { BDS } \\ \text { Yamna Nadeem }^{4} & \text { BDS } \\ \text { Amna Nayyar }^{5} & \text { BDS }\end{array}$

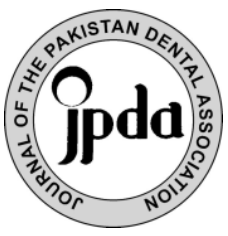

\begin{abstract}
:
INTRODUCTION: Perception and the self-esteem of the individuals in regards to their dentition was investigated and compared to check what impact it has on one's smile. The comparison is made on three different levels of professionalism.

METHODOLOGY: This cross-sectional study was conducted at Dow University of Health Sciences, Karachi, Pakistan. Convenience sampling was used to select orthodontists, general dental students and non-dental students, mainly medical and pharmacy students in the premises of Dow University of Health Sciences, Ojha Campus. Sample size of the study was 580. The proforma consisted of questions and pictures, which were rated from 0 to 100 (using the Visual Analogue Scale), with 0 being least attractive to 100 being most attractive. The VAS values representing the aesthetic perception were statistically analyzed using a mean and one-way ANOVA.
\end{abstract}

RESULT: Comparison among three different groups (non-dental students, dental students and orthodontists) was done, and the results were significant. Accordingly orthodontist response show that they are more pleased with their appearance (85\%) as compared to than dental (19\%) and non-dental students (30\%).

CONCLUSION: There was a significant difference found when compared other two responses with the orthodontist one's. With almost similar result found between dental student and non-dental.

KEYWORDS: Perception, smile, esthetics, VAS.

HOW TO CITE: Sardar KP, Shahid A, Moiz A, Nadeem Y, Nayyar A. Perception of Smile by Orthodontists, Non-Dental and Dental Students: A Comparative Study. J Pak Dent Assoc 2017; 26(1): 1-5

Received: 1 December 2016, Accepted: 17 February 2017

\section{INTRODUCTION}

$\mathrm{T}$ The word Esthetics means something that looks beautiful, and which is appreciated by others., These days, people are becoming more conscious regarding their appearance and esthetics, especially regarding facial esthetics.

Contemporary dentistry pays a a lot of emphasis on esthetics at all levels of esthetics i.e. macro,mini, and micro esthetics of smile.. ${ }^{1}$

${ }^{1}$ Vice Principal (DIKIOHS), Assistant Professor, Department of Science of Dental Materials, Dr.Ishrat-ul-Ebad Khan Institute of Oral Health Sciences, Dow University of Health Sciences, Karachi, Pakistan

${ }^{2-5}$ House-officer, Dr. Ishrat-ul-Ebad Khan Institute of Oral Health Sciences (DIKIOHS),

Corresponding author: "Dr. Ahmed Moiz"<ahmed.mz93@gmail.com>
A number of patients approach the dentist primarily due to their problem associated with their appearance.

It's imperative for the dental students to be able to identify individual patients' esthetic needs, demands and expectations. The element of esthetics has to be factored into treatment planning and clinical decisions making.

Although, appraisal of smile esthetics is a subjective entity but it's important for the dentists tro understand the fundamentals of smile esthetics. This helps them understand the patients' esthetic needs and select suitable interventions for providing the solutions. Facial attractiveness and smile attractiveness appear strongly connected to each other. The fact is that in social interaction, one's attention is mainly directed toward the mouth and eyes of the speaker's face. ${ }^{12}$ Parameters such as smile arc, tooth 
and gingival display, presence of buccal corridor space (BCS), gingival esthetics, tooth color, occlusal plane inclination, coincidence of facial and dental midlines, and proportional alignment and harmony of teeth constitute the smile esthetics.

\section{OBJECTIVES}

the 1- To assess perception of smile esthetics in their own teeh among three groups of participants (orthodontists, dental students and non-dental students).

2- To assess the perception of a perfect smile among three groups of respondents (orthodontists, dental students and non-dental students)

\section{METHODOLOGY}

A cross sectional study was conducted at Dow University of Health Sciences, Karachi, Pakistan. Convenience sampling was employed to select three strata of participants namely; orthodontists, under graduate dental students, and non -dental i.e. pharmacy and medical students. Sample size was computed on the basis of adjusting the margin of error (d) at 5\% and confidence of interval on $95 \%$, least $50 \%$ proportion of response distribution with relative precision of $8.5 \%$, the minimum sample size turned out to be 533 .

The proforma consisted of questions related to selfesteem opinion regarding oneself. The second part had clinical pictures defining different attributes, which was rated from 0 to 100 (using the Visual Analogue Scale), with 0 being least attractive to 100 being most attractive.

We assessed esthetic appraisals of smile by there groups of respondent while focusing on six parameters of smile esthetics. These were: smile arc, tooth and gingival display, presence of buccal corridor space (BCS), teeth length, coincidence of facial and dental midlines, and proportional alignment and harmony of teeth. .

participants were only given pictures and were asked to rate the images.

The data was computed on SPSS 16.0 a. Descriptive statistics were computed. One way ANOVA was applied to ascertain whether any noteworthy difference existed among the mean scores of each photograph by all the assessors.

Questionnaire which is used to assess them is given below:

\section{Comparing with your smile Rate the pictures below:}
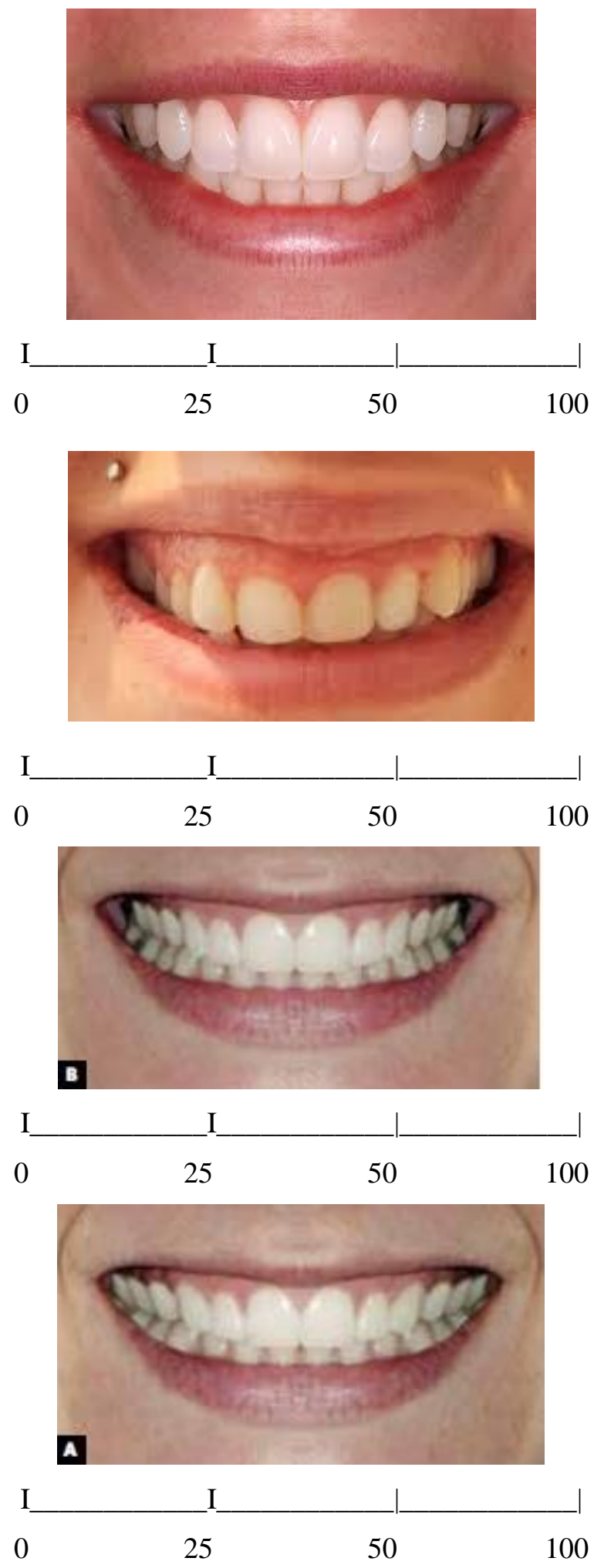


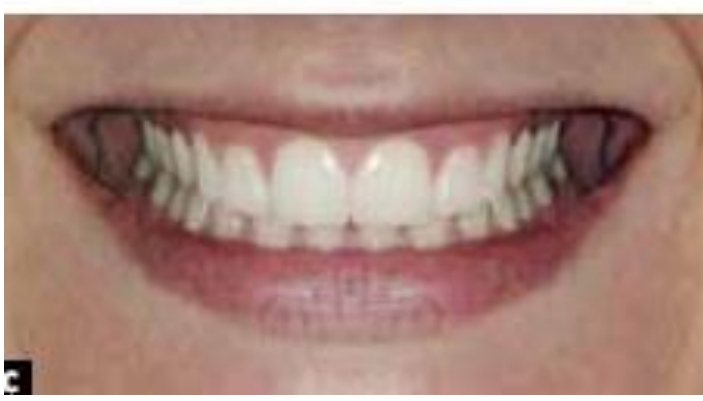

\section{I}

0

I

25

50

100

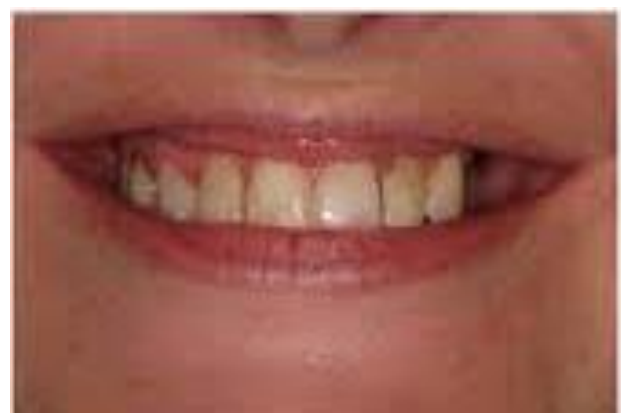

I

$$
0
$$

25

50

100

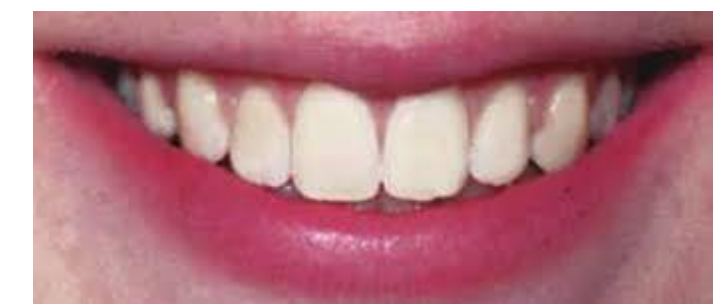

I

I

0

25

50

100

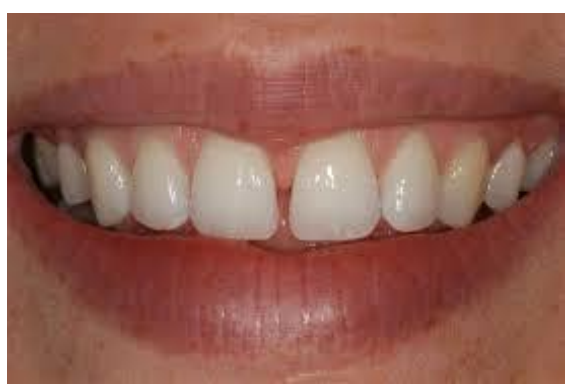

I

I

0

25
50

100
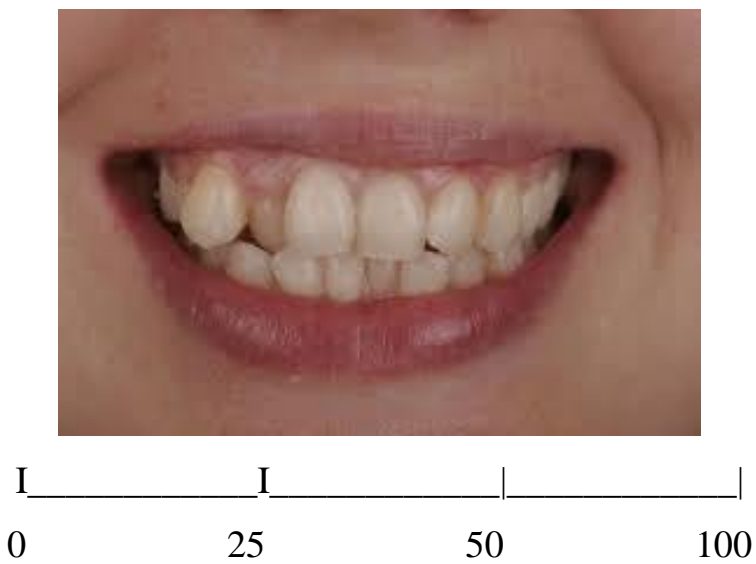

RESULTS

The total number of participants in the study was 533 .. The valid responses were obtained from 314 dental students, 180 non-dental students and 39 Orthodontists

After reviewing the self -esteem questionnaire, the orthodontists' responses showed that they were more pleased with their appearance $(85 \%)$ compared to dental (19\%) and non-dental students. Nearly 30\% Orthodontists demonstrated higher self-confidence as compared to the two other groups in regards to their dental esthetics.

Majority of orthodontists $(76.9 \%)$ were pleased with their tooth alignment and positioning while (50\%) of the dental $(36.9 \%)$ and non-dental $(41.7 \%)$ expressed that they needed orthodontic treatment. Of the three groups, $29.3 \%$ dental students, $36.7 \%$ non-dental students and $38.5 \%$ orthodontists had been suggested orthodontic treatment in the past.

The non-dental students did not feel good about the appearance of their teeth $(46 \%)$ while orthodontists have a more neutral view about it (70\%). Dental students were more or less divided equally amongst those who felt good about their teeth $(37 \%)$ and those who did not (41\%)

When asked about what they would like to change about their teeth the most, the major response for dental students $(49.1 \%)$ and non-dental students (57.1) was changing the alignment of their teeth. However, $80 \%$ orthodontists chose that they would like to change the color of their teeth.

Results revealed no significant difference in the perception of dental and non-dental students and relation to the parameters of smile.

No significant difference was detected between the perceptions of dental and non-dental students however; there was a significant difference when compared to the responses 
of orthodontists Significant differences ( $\mathrm{P}$ value $<0.001$ ) in the responses was observed for VAS of gummy smile and wide buccal corridor with the orthodontists giving a lower score (16.9 and 14.7, respectively) as compared to the dental (37.8 and 46.2, respectively) and non-dental students (33.8 and 43.3 , respectively).

\section{DISCUSSION}

In our study the response was assessed using a VAS scale, which showed the three groups had somewhat similar scores (for all the parameters of a smile except for gummy smile and buccal corridor ( $p$ - value $<0.001$ ), for which the orthodontists gave a lower scores compared to dental and non-dental students.

Dustin and Ronald reported that smile esthetics are not influenced by the presence of buccal corridors. ${ }^{11}$ However, Parakesh and Fields ${ }^{14}$ iterated that orthodontists rated smiles with excessive buccal corridors as being less attractive.

In a recent study by Rabia Bilal ${ }^{2}$, there was no significant difference noted among orthodontists, general dentists \& dental students for smile attractiveness . The dental students were similar to orthodontists in rating the smile arc as the most preferred paramaterry, orthodontists. The preference for the rest of the attributes was different: Smile arc $(53.59 \%)$, followed by smile line $(18.63 \%)$, incisal show $(15.15 \%)$, buccal corridor $(5.71 \%)$, tooth color $(3.97 \%)$ and the least common being gingival color $(2.98 \%)^{2}$

Krishnan et al. ${ }^{9}$ reported that there was no difference in found between the specialists and laypersons. However, Kokich et al. showed that between specialists, orthodontists are more critical about smile evaluation and detecting minute discrepancies. ${ }^{10}$ In a study conducted in Saudi Arabia by Hadeel A Mokhtar et al, laypeople perceived a change in attractiveness when the distance from gingiva to lip was 3.0 $\mathrm{mm}$ or greater. However, dentists did not rate excess gingival display as unattractive, even with a maximum of 4.0 mm. ${ }^{6}$

In a study conducted by Cotrim ER et al.,$^{8}$ the groups (orthodontists, clinicians and laypersons) emphasized upon different features contributing to smile unpleasantness. Orthodontists stressed on little gingival display, whereas laypersons highlighted disproportionate teeth. Other clinicians emphasized on the yellow teeth hence revealing that all focused on different parameters of the smile.

- The general trend indicated that orthodontists were more confident regarding their appearance and dental esthetics and they also displayed more knowledge regarding various smile parameters.
Marta Liliana et al., ${ }^{5}$ established that over half of the participants selected tooth alignment as the chief factor required for an aesthetically desirable smile.

Patients and dental students considered tooth color the second most important factor required for esthetic purpose after tooth alignment. Our results were somewhat similar, as dental and non-dental students chose alignment as the most important factor, whereas orthodontists opted for color as being more important.

Few limitations in our research were that majority of questionnaire was filled up by females who usually are more cautious about esthetics. Secondly, we only took orthodontists in the study as while clinicians belonging to other dental specialties such as Prosthodontists and Operative Dentists might have demonstrated different perceptions about the esthetic appraisal.

\section{CONCLUSIONS}

There was no significant difference detected between the perception and self-esteem in relation with dental esthetics for dental and non-dental students, however there was a significant difference when students were compared with the orthodontists. Orthodontists were able to scrutinize and identify smile attributes more clearly, which was due to their expertise in the discipline gained from specialist education and training.

\section{AUTHORS' CONTRIBUTION:}

KPD: supervisor.

AS: Write up, research conduct (questionnaire making) and results.

AM: Research conduct (questionnaire making), discussion and statistics.

YN: Methodology and research conduct (Proforma distribution).

ZA: Introduction and research conduct (Proforma distribution).

AN: Editing and conclusions.

\section{REFERENCES}

1. Omar H, Tai YT. Perception of smile esthetics among dental and nondental students. J Edu Ethics Dent. 2014;4:54-60. 
2. Bilal R. Perception of smile by orthodontists, general dentists and dental students: A Comparative study. Pak Oral Dent J. 2015;35:208-12.

3. Musskopf ML, Rocha JM, Rosing CK. Perception of smile esthetics varies between patients and dental professionals when recession defects are present. Braz dent j. 2013;24:385-90.

4. Cotrim ER, Vasconcelos Júnior ÁV, Haddad AC, Reis SA. Perception of adults' smile esthetics among orthodontists, clinicians and laypeople. Dent press $\mathrm{j}$ orthod. 2015;20:40-4.

5. Musskopf ML, Rocha JM, Rosing CK. Perception of smile esthetics varies between patients and dental professionals when recession defects are present. Braz dent j. 2013;24:385-90.

6. Mokhtar HA, Abuljadayel LW, Al-Ali RM, Yousef M. The perception of smile attractiveness among Saudi population. Clin cosmetic investigat dent. 2015;7:17.

7. Omar H, Tai YT. Perception of smile esthetics among dental and nondental students. J Edu Ethics Dent. 2014 $1 ; 4: 54$.

8. Cotrim ER, Vasconcelos Júnior ÁV, Haddad AC, Reis SA. Perception of adults' smile esthetics among orthodontists, clinicians and laypeople. Dent press $\mathrm{j}$ orthod. 2015;20:40-4.
9. Krishnan V, Daniel ST, Lazar D, Asok A. Characterization of posed smile by using visual analog scale, smile arc, buccal corridor measures, and modified smile index. Am J Orthod Dentofac Orthop. 2008;133:515-23.

10. Kokich VO, Kokich VG, Kiyak HA. Perceptions of dental professionals and laypersons to altered dental esthetics: asymmetric and symmetric situations. Am J Orthod Dentofac Orthop. 2006;130:141-51.

11. Faure JC, Rieffe C, Maltha JC. The influence of different facial components on facial aesthetics. Eur $\mathrm{J}$ Orthod. 2002;24:1-7.

12. Van der Geld P, Oosterveld P, Van Heck G, KuijpersJagtman AM. Smile attractiveness: self-perception and influence on personality. Angle orthod. 2007;77:759-65.

13. An KY, Lee JY, Kim SJ, Choi JI. Perception of maxillary anterior esthetics by dental professionals and laypeople and survey of gingival topography in healthy young subjects. Int J Periodont Restorat Dent. 2009;29: 534-41.

14. Parekh SM, Fields HW, Beck M, Rosenstiel S. Attractiveness of variations in the smile arc and buccal corridor space as judged by orthodontists and laymen. Angle orthod. 2006;76:557-63. 